
$\frac{11 / 9.91}{9-3}$ (2)

DOE/NASA/16310-16

NASA TM-105171

AIAA-91-3530

\title{
Advanced Materials for Space Nuclear Power Systems
}

Robert H. Titran and Toni L. Grobstein

National Aeronautics and Space Administration

Lewis Research Center

and

David L. Ellis

Case Western Reserve University

Cleveland, Ohio 44106

Work performed for

U.S. DEPARTMENT OF ENERGY

Office of Nuclear Energy

Prepared for the

Conference on Advanced Space Exploration Initiative Technologies cosponsored by the AIAA, NASA, and OAI

Cleveland, Ohio, September 4-6, 1991

\section{MASTER}




\section{DISCLAIMER}

This report was prepared as an account of work sponsored by an agency of the United States Government. Neither the United States Government nor any agency Thereof, nor any of their employees, makes any warranty, express or implied, or assumes any legal liability or responsibility for the accuracy, completeness, or usefulness of any information, apparatus, product, or process disclosed, or represents that its use would not infringe privately owned rights. Reference herein to any specific commercial product, process, or service by trade name, trademark, manufacturer, or otherwise does not necessarily constitute or imply its endorsement, recommendation, or favoring by the United States Government or any agency thereof. The views and opinions of authors expressed herein do not necessarily state or reflect those of the United States Government or any agency thereof. 


\section{DISCLAIMER}

Portions of this document may be illegible in electronic image products. Images are produced from the best available original document. 


\section{DISCLAIMER}

This report was prepared as an account of work sponsored by an agency of the United States Government. Neither the United States Government nor any agency thereof, nor any of their employees, makes any warranty, express or implied, or assumes any legal liability or responsibility for the accuracy, completeness, or usefulness of any information, apparatus, product, or process disclosed, or represents that its use would not infringe privately owned rights. Reference herein to any specific commercial product, process, or service by trade name, trademark, manufacturer, or otherwise, does not necessarily constitute or imply its endorsement, recommendation, or favoring by the United States Government or any agency thereof. The views and opinions of authors expressed herein do not necessarily state or reflect those of the United States Government or any agency thereof.

Printed in the United States of America

Available from National Technical Information Service

U.S. Department of Commerce

5285 Port Royal Road

Springfield, VA 22161

NTIS price codes 1

Printed copy:

Microfiche copy: $\mathrm{A03}$

${ }^{1}$ Codes are used for pricing all publications. The code is determined by the number of pages in the publication. Information pertaining to the pricing codes can be found in the current issues of the following publications, which are generally available in most libraries: Energy Research Abstracts (ERA); Government Reports Announcements and Index (GRA and I); Scientific and Technical Abstract Reports (STAR); and publication, NTIS-PR-360 available from NTIS at the above address. 


\section{Advanced Materials for Space Nuclear Power Systems}

Robert H. Titran and Toni L. Grobstein

National Aeronautics and Space Administration

Lewis Research Center

Cleveland, Ohio 44135

and

David L. Ellis

Case Western Reserve University

Cleveland, Ohio 44106

Work performed for

U.S. DEPARTMENT OF ENERGY

Office of Nuclear Energy

Washington, D.C. 20545

Under Interagency Agreement DE-Al03-86SF16310

Prepared for the

Conference on Advanced Space Exploration Initiative Technologies cosponsored by the AIAA, NASA, and OAI

Cleveland, Ohio, September 4-6, 1991 


\title{
ADVANCED MATERIALS FOR SPACE NUCLEAR POWER SYSTEMS
}

\author{
Robert H. Titran and Toni L. Grobstein \\ National Aeronautics and Space Administration \\ Lewis Research Center \\ Cleveland, Ohio 44135 \\ and \\ David L. Ellis \\ Case Western Reserve University \\ Cleveland, Ohio 44106
}

\begin{abstract}
$\underline{\text { Abstract }}$
Research on monolithic refractory metal alloys and on metal matrix composites is being conducted at the NASA Lewis Research Center, Cleveland, Ohio, in support of advanced space power systems. The overall philosophy of the research is to develop and characterize new high-temperature power conversion and radiator materials and to provide spacecraft designers with material selection options and design information. Research on three candidate materials (carbide strengthened niobium alloy PWC-11 for fuel cladding, graphite fiber reinforced copper matrix composites $(\mathrm{Gr} / \mathrm{Cu})$ for heat rejection fins, and tungsten fiber reinforced niobium matrix composites $(\mathrm{W} / \mathrm{Nb})$ for fuel containment and structural supports) considered for space power system applications is discussed. Each of these types of materials offers unique advantages for space power applications.
\end{abstract}

\section{$\underline{\text { Introduction }}$}

The increasing size and complexity of space-based hardware and advanced lunar and planetary missions mandates increased power system needs. The development of advanced space power systems is a critical enabling technology. Although several different power systems are under consideration, they all share the same common features which include a heat source, a power conversion system, and a heat rejection system. Since maximum specific power is a key goal of all power systems, the main design requirements for all these systems include high-temperature operation and minimum system mass.

Research on refractory metals and metal matrix composites is being conducted at the NASA Lewis Research Center, Cleveland, Ohio in support of advanced space power and propulsion systems. The objective of this research is to develop and characterize new high-temperature power conversion and radiator materials to provide space power system designers with design information and material selection options. Rather than developing materials for a particular mission, we are attempting to anticipate needs and develop generally applicable materials for future applications.

The following overview will discuss research on carbide strengthened niobium alloys and two candidate metal matrix composites (MMC's). Specifically we will cover on-going research on the thermal stability and creep strength of niobium-zirconium-carbon (Nb-Zr-C) alloys for fuel cladding, the creep strength of tungsten fiber reinforced niobium matrix composites $(\mathrm{W} / \mathrm{Nb}$ ) for advanced systems fuel cladding and high temperature structures, and the thermal conductivity and thermal expansion of graphite fiber reinforced copper matrix composites $(\mathrm{Gr} / \mathrm{Cu})$ for heat rejection radiator fins. 
$\underline{\text { Research and Discussion }}$

$\underline{\text { Refractory Metal Alloys Technology }}$

The SP-100 space nuclear reactor program selected the $\mathrm{Nb}-1 \% \mathrm{Zr}$ alloy as the nuclear assembly test (NAT) material for the ground engineering system. NASA in concert with General Electric-San Jose Operations, Oak Ridge National Laboratory, and Westinghouse Corporation is conducting a series of studies to define the thermal stability and creep behavior of this alloy. These studies have shown that the $\mathrm{Nb}-1 \% \mathrm{Zr}$ alloy has marginal strength to meet the design requirements of 7 to 10 years, $1350 \mathrm{~K}$, 2-percent creep strength for the SP-100 reactor system. To improve the $\mathrm{Nb}-1 \% \mathrm{Zr}$ alloy, such things as a large grain size microstructure $(80 \mu \mathrm{m})$ along with minor additions (in the parts per million range) of carbon, nitrogen, tantalum, and tungsten are being explored. An alternate approach is the development and evaluation of a higher strength alloy that will still meet the liquid metal compatibility requirements for SP-100. We have selected an alloy similar to PWC-11, which is the nominal Nb-1\% Zr composition but containing carbon additions up to 0.11 percent. $^{1-3}$ Creep tests on material containing from 0.06 to $0.11 \% \mathrm{C}$ indicate that this alloy should posess required creep strength and microstructural thermal stability at conditions believed to be similar to those encountered in SP-100 fuel pin claddings. Both $\mathrm{Nb}-1 \% \mathrm{Zr}$ and $\mathrm{PWC}-11$ are being tested at $1350 \mathrm{~K}$ and stress levels of 10 and $34.5 \mathrm{MPa}$. With test data in excess of $34000 \mathrm{~h}$, as shown in Fig. 1, PWC-11 containing only $0.062 \% \mathrm{C}$ exhibited essentially no creep deformation while the $\mathrm{Nb}-1 \% \mathrm{Zr}$ reached 1-percent creep in $11000 \mathrm{~h}$ and 2-percent creep in $18800 \mathrm{~h}$. PWC-11 with $0.10 \% \mathrm{C}$ has even better creep strength as shown in Fig. 2. Tests at $1350 \mathrm{~K}$ and 34.5 Mpa clearly demonstrate the creep strength superiority of the $0.10 \% \mathrm{C}$ PWC-11 alloy to PWC-11 containing only $0.062 \% \mathrm{C}$.

The high-temperature $\left(0.5 \mathrm{~T}_{\mathrm{m}}\right)$ creep strength of PWC-11, relative to the order of magnitude lower carbon content $\mathrm{Nb}-1 \% \mathrm{Zr}$ alloy has been attributed to the presence of a very fine precipitate of $(\mathrm{Zr}, \mathrm{Nb}) \mathrm{C}$ ranging in size from submicron to about $10 \mu \mathrm{m}$ in diameter. $^{4,5}$ In the as-rolled and annealed conditions, the PWC-11 microstructure predominantly consists of relatively coarse $(>1 \mu \mathrm{m})$ orthorombic carbides of $\mathrm{Nb}_{2} \mathrm{C}$. Prolong exposure of the material to elevated temperatures with or without an applied stress gives rise to the conversion of $\mathrm{Nb}_{2} \mathrm{C}$ particles to fine face-centered cubic carbides of $\mathrm{Zr}$ and $\mathrm{Nb}$, very finely distributed throughout the matrix. The $(\mathrm{Zr}, \mathrm{Nb}) \mathrm{C}$ carbides have a lattice parameter ranging from about 0.458 to $0.468 \mathrm{~nm}$ with an accompanying $\mathrm{Zr}: \mathrm{Nb}$ ratio of about 70:30. The characterization of the precipitates in PWC-11 is given in Table $\mathrm{I}$. These fine particles provide excellent microstructure stability and excellent creep strength at temperatures as high as $1350 \mathrm{~K}$. Using the Orr-Sherby-Dorn ${ }^{6}$ parameter, 1- and 2-percent creep strain was temperature compensated and correlated with the applied stress (Fig. 3). Based on the creep tests conducted to date, projections have been made for the relative stress to limit creep strain to 2-percent in a 7 -year time frame and compared to the design requirements for SP-100. The results are shown in Fig. 4. PWC-11 is a factor of four times stronger than the $\mathrm{Nb}-1 \% \mathrm{Zr}$ tested ( 21 to $5 \mathrm{MPa}$ at $1350 \mathrm{~K}$ ) over the SP-100 design temperature range of 1350 to $1380 \mathrm{~K}$ and affords excellent growth potential over the present SP-100 design criterion.

\section{$\underline{\text { Refractory Metal Composites Technology }}$}

The objective of this part of our program is to develop and characterize refractory metal composites for future space power systems where requirements for several hundred kilowatts to megawatts of electricity will need to be met. Currently, monolithic niobiumbased alloys such as Nb-1\% Zr and PWC-11 are specified for components in the power conversion system of space nuclear power systems. Tungsten fiber reinforced niobium metal-matrix composites $(\mathrm{W} / \mathrm{Nb})$ are being considered for future applications where higher temperature and higher stress conditions may 
exist to reach these higher power requirements. W/Nb composites offer potential for high tensile and creep strength applications up to $1700 \mathrm{~K}^{7,8}$

$\mathrm{W} / \mathrm{Nb}$ composites were fabricated by the Lewis-patented arc-spray monotape technique. ${ }^{6}$ This process, schematized in Fig. 5, consists of wrapping the reinforcing fibers on a drum, placing the drum in an air-tight chamber, evacuating the chamber, and backfilling it with argon. Next, wires of the matrix composition are brought together in the arc-spray gun, an arc is struck between them, and pressurized argon blows the molten matrix covering the fibers; the resulting structure is a "monotape" consisting of one layer of fibers in a matrix. Layers of monotapes then can be hot pressed or hot isostatically pressed (HIP), producing a fully densified consolidated structure with negligible fiber/matrix interfacial reaction (Fig. 6). Composite panels can be fabricated with an infinite range of angle-plies using this technique. In addition, tubing can be fabricated using these monotapes in conjunction with HIPing (Fig. 7).

A macrograph of the microstructure of a ST300/Nb-1\%Zr composite is shown in Fig. 8. This panel contains $35 \mathrm{vol} \%$ of $200 \mu \mathrm{m}$ diameter fibers; however, the fiber spacing, fiber diameter, and the volume percent can be varied for the particular application. The comparison of the UTS/density ratio of $\mathrm{W} / \mathrm{Nb}$ composites with 42 vol \% 218CS or ST300 tungsten fibers in Fig. 5 shows that the composites have a ratio two to five times that of the monolithic $\mathrm{Nb}-1 \% \mathrm{Zr}$ or unalloyed $\mathrm{Nb}$.

The $218 \mathrm{CS}$ wire is a commercially available, potassium-doped lamp filament wire, whereas the stronger ST300 wire contains a fine dispersion of $1.5 \mathrm{wt} \% \mathrm{ThO}_{2}$. Also, the composites made with unalloyed niobium were for modeling purposes only; zirconium must be added to niobium in order to insure materials compatibility in liquid lithium metal cooled systems. For example, if any oxygen is present in the niobium grain boundaries, the liquid metal will leach it out. The lithium can eventually permeate the entire thickness of the container resulting in "weeping" on the outer wall surface. ${ }^{9}$ The zirconium ties up the oxygen and keeps it in the niobium matrix.

One challenge in the use of these materials is the possible degradation in properties after long times at elevated temperature due to interdiffusion between the fiber and matrix. Since interdiffusion between tungsten and niobium results in a continuous solid solution, it is not a catastrophic process. It may, however, cause recrystallization of the tungsten fiber which would reduce the strength of these fibers. The projected life (greater than $60000 \mathrm{~h}$ ) and temperature (up to $1700 \mathrm{~K}$ ) requirements for the composites could result in a reduction in creep strength of the $\mathrm{W} / \mathrm{Nb}$ composites during service.

A comparison of the minimum creep rates of the composites tested at 1400 and $1500 \mathrm{~K}$ with that for the arc-sprayed niobium monolithic material tested at $1400 \mathrm{~K}$ is made in Fig. 9. It is evident that the composites creep at a much lower rate than the niobium matrix material. Noting that the strain- and strain-rate compatibility must be maintained at the fiber/matrix interface during creep of a composite subjected to uniaxial loading, it is possible to estimate the relative magnitude of the stress on the matrix using Fig. 9. For example, at $1400 \mathrm{~K}$ the $\mathrm{ST} 300 / \mathrm{Nb}$ composites exhibit a minimum creep rate of about $1 \times 10^{-8}$ $\mathrm{s}^{-1}$ at $250 \mathrm{MPa}$. Using the strain-rate compatibility arguments, the data in Fig. 9 suggest that a stress of about $15 \mathrm{MPa}$ would enable the niobium matrix to creep at the same rate. It can be shown using the rule of mixtures, that the corresponding stress on the matrix is only about 3 percent of the total applied stress acting on a composite containing 50 vol \% fibers. This means a first order prediction of creep behavior of the composites can be described by the creep equations for the reinforcing fibers. The minimum creep rate of the composites can thus be equated to the power creep behavior as follows: 


$$
\begin{gathered}
\dot{\varepsilon}_{\mathrm{m}}=A \sigma^{\mathrm{n}} \mathrm{e}^{-\frac{Q}{R T}} \\
\sigma=\sigma_{f}=\frac{\sigma_{\mathrm{C}}}{v_{f}} \\
\dot{\boldsymbol{\varepsilon}}_{\mathrm{m}}=\mathrm{A}\left(\frac{\sigma_{\mathrm{C}}}{v_{f}}\right)^{\mathrm{n}} \mathrm{e}^{-\frac{\mathrm{Q}}{R T}}
\end{gathered}
$$

where
$\sigma \quad$ the stress on the composite
$\sigma_{f}$ the stress on the fiber assuming that the fiber carries the total load
$v_{\mathrm{f}} \quad$ the volume fraction of fiber
Q the apparent activation energy
n the creep-rate stress exponent

A a constant for the fiber

The calculated composite creep activation energy $Q$ of 465 to $490 \mathrm{~kJ} /$ mole agrees with results for other forms of tungsten tested in this temperature range. The creep rate stress exponent $n$ for the ST300 reinforced composites ranged between 5 and 6 , which is in agreement with values predicted by simple theories of dislocation climb where $\mathbf{n}$ is about 5. It is unlikely that grain boundary diffusion creep or grain boundary sliding controls creep because of the oriented grain structure of the wires.

The creep-rupture behavior of the composite was calculated using the rule of mixtures/power law creep relationship. The rupture data for the fiber, the matrix and the measured values are plotted along with the calculated rupture strength of the composite in Fig. 10. It is extremely encouraging to note that the measured values of the rupture times of the composite exceed what the rule of mixtures predicts.

The transverse properties of any unidirectionally reinforced composite are far lower than their axial properties. In fact, the transverse properties of $\mathrm{W} / \mathrm{Nb}$ composites have been shown to be only slightly better than the properties of the unreinforced matrix. It is possible to alleviate this disparity by angle-plying the tungsten fibers to increase the transverse properties. It is obvious, though, that this will correspondingly decrease the axial properties. It is significant to note, however, that angle-plying the fibers $\pm 15^{\circ}$ results in only about a 20 percent decrease in the axial composite creep strength (Fig. 11). It is also apparent from this figure that the properties of even those panels with $\pm 15^{\circ}$ angle-plied fibers exceed the creep properties of the monolithic PWC-11 alloy by a factor of four and the $\mathrm{Nb}-1 \% \mathrm{Zr}$ alloy by an order of magnitude. Although the effect of angle plying on the transverse strength has not yet been measured, it is expected to have a corresponding increase.

\section{Graphite/Copper Composites Technology}

Space power system radiator fins require a material with high thermal conductivity, low to moderate density, and good stiffness. Several materials can be used for space power system applications. For applications where mass is a concern, the density compensated specific thermal conductivity (thermal conductivity divided by density) is a better measure of the merit of a material than the absolute thermal conductivity. The specific thermal conductivity of six potential radiator fin materials are shown in Fig. 12. Solar power systems have radiator fins operating between 300 and $600 \mathrm{~K}$. While nuclear power system radiator fins can operate at temperatures as low as $300 \mathrm{~K}$, most systems have fins operating between 450 and $1050 \mathrm{~K}$. For low temperature applications such as solar power systems, aluminum reinforced with ultrahigh modulus 
(UHM) pitch-based fibers ${ }^{10}$ are clearly the material of choice. It combines high thermal conductivity from both the matrix and the fiber with low density. Unfortunately, the pure aluminum matrix softens considerably above room temperature, limiting the maximum use temperature of these composites. Even if strength is not a consideration, the aluminum will melt at temperatures above $993 \mathrm{~K}$.

Even though copper has a high density $(8.92 \mathrm{~g} / \mathrm{cc}),{ }^{11}$ the specific thermal conductivity of copper is very good compared to most materials. The primary problem with using copper for a radiator fin material is its low stiffness. Beryllium is often considered for use in aerospace applications because of its low density $(1.85 \mathrm{~g} / \mathrm{cc})$ and high stiffness $(303.6 \mathrm{GPa}) .^{12}$ Because of its low density, the specific properties of beryllium are very high. But, as shown in Fig. 12, the density compensated thermal conductivity of beryllium is actually less than that of $\mathrm{Gr} / \mathrm{Cu}$ above $450 \mathrm{~K}$.

Titanium and niobium alloys have been proposed as high temperature fin materials for nuclear space power systems radiator fins operating above $700 \mathrm{~K}$ where the use temperature of Be and other materials currently available is exceeded. As can be clearly seen in Fig. 12, their specific thermal conductivities are very low.

\section{$\mathrm{Gr} / \mathrm{Cu}$ composites are being considered} for applications with operating temperatures above $450 \mathrm{~K}$. Previous work ${ }^{13}$ has shown that the thermal conductivity of the composites is as good or better than copper. The dynamic modulus of P100 graphite fiber reinforced composites was also determined to be slightly over $300 \mathrm{GPa}$ up to $650 \mathrm{~K}$. The density of $\mathrm{Gr} / \mathrm{Cu}$ composites of interest range from 4.5 to $5.5 \mathrm{~g} / \mathrm{cc}$ for 60 and $40 \mathrm{vol} \% \mathrm{Gr} / \mathrm{Cu}$ composites, respectively. The combination of high thermal conductivity, and moderate density give the $\mathrm{Gr} / \mathrm{Cu}$ composites great potential for use as space power radiator fins.
The thermal expansion of the radiator fin material is also a concern since the fins will be brazed to a heat pipe. A large thermal expansion mismatch can lead to failure of the braze joint and loss of radiator surface. The thermal expansion mismatch can be minimized since P100 graphite fibers have a small, negative coefficient of thermal expansion (CTE),${ }^{14}$ while copper has a much larger, positive CTE. ${ }^{15}$ Varying the fiber orientation and volume fraction of the fibers leads to a CTE that minimizes the stresses in the braze joint.

Under normal conditions graphite and copper do not react and do not form any diffusional bond across the interface. ${ }^{16}$ As a result the mechanical load is transferred across the interface by friction and limited mechanical bonding. This is important in thermal expansion where the stresses generated from the CTE mismatch can lead to slippage at the interface or yielding of the matrix as will be seen later.

\section{Production of $\mathrm{Gr} / \mathrm{Cu}$ Composites}

For this study P100 pitch-based graphite fibers were selected for the reinforcing graphite fiber. The arc spray process developed at NASA Lewis ${ }^{6}$ shown in Fig. 6 was used to produce the samples tested in this study. In the arc spray process, graphite fibers coated with copper are passed through a series of baths to remove surface contamination and wound onto a drum. The volume fraction of graphite fiber was controlled by varying the coating thickness on the fibers. A thin layer of pure copper is arc sprayed onto the fiber to produce a monotape such as the one shown in Fig. 13. These monotapes are easily handleable and can be precisely laid up in the desired architecture. Four to eight layers of monotape were used to produce samples up to $100 \mathrm{~mm}$ wide by $200 \mathrm{~mm}$ long by 1- to 2-mm-thick for testing. Actual fiber contents of the samples was determined after consolidation from specific gravity 
measurements. The composites have a good distribution of fibers in the matrix. Good consolidation was achieved with new grain boundaries and twins extending across the prior particle boundaries (Fig. 14). No voids were observed.

In addition to the unidirectional $\mathrm{Gr} / \mathrm{Cu}$ composites, cross-plied $\mathrm{Gr} / \mathrm{Cu}$ composites have been produced using the arc spray process. These composites contain eight layers. The outer four layers were oriented parallel to the length of the plate. This was defined as the longitudinal or $0^{\circ}$ direction. The inner four layers were oriented perpendicular to the outer fibers and parallel to the width of the plate. This was defined as the long transverse or $90^{\circ}$ direction. Samples were taken from this plate for thermal expansion testing.

Due to the anisotropy in the UHM graphite fibers, the thermal conductivity of the composites will differ greatly depending whether the heat flow is parallel or perpendicular to the fiber axis. The thermal conductivity was therefore tested in the longitudinal, long transverse, and short transverse directions. The longitudinal direction of the unidirectional composites is defined as the direction parallel to the fiber axis. The long transverse direction is the width of the plate, and the short transverse direction is through the thickness of the plate. Figure 15 shows the three directions. Figure 15 also shows how a typical composite could be angle-plied to improve long transverse properties.

Thermal conductivity testing was conducted at the Thermophysical Properties Research Laboratory (TPRL) at Purdue University using the laser flash technique. ${ }^{17}$ Thermal expansion tests in the longitudinal and long transverse directions were conducted over a temperature range of 295 to $1073 \mathrm{~K}$ using a Netzsch dilatometer at NASA Lewis.

\section{Thermal Conductivity of $\mathrm{Gr} / \mathrm{Cu}$ Composites}

The results from the thermal conductivity testing of the unidirectionally reinforced
$\mathrm{Gr} / \mathrm{Cu}$ composites produced by the arc spray process are shown in Fig. 16. The longitudinal values fall in a relatively narrow band with values near that of copper. This is because the thermal conductivity of the fibers in the direction of the fiber axis is near the value for copper. Therefore replacing copper with graphite fiber does not result in a change in the composite thermal conductivity.

The thermal conductivities for the short transverse direction are also presented in Fig. 16. The transverse direction samples have lower thermal conductivities and show a decrease in thermal conductivity with increasing fiber content. The decrease in conductivity is caused by the highly anisotropic nature of the UHM graphite fibers. ${ }^{18}$ While the thermal conductivity of the fibers in the axial direction is high, the thermal conductivity in the radial direction is near zero. Because of this the heat is conducted almost exclusively by the copper matrix in the transverse directions. With the introduction of more fibers, the path length for the heat to travel increases and the thermal diffusivity decreases, decreasing the thermal conductivity.

The thermal conductivities of the long transverse directions were also measured. The values were 25 to $35 \mathrm{~W} / \mathrm{mK}$ higher than the values for the short transverse directions. This difference is the result of the arc spray processing. In the long transverse direction there are thin layers of copper rich material deposited during the arc spraying in the direction of the heat flow. These layers allow for easier diffusion of the heat than in the short transverse direction. With the increase in thermal diffusivity, the thermal conductivity increases.

For the reduction of mass in space power thermal management systems, the density dependent specific thermal conductivity is a more important design criterion than the absolute thermal conductivity. The effect of fiber content on the longitudinal and short transverse specific thermal conductivities at $800 \mathrm{~K}$ is presented in Fig. 17. In the 
longitudinal direction, the specific thermal conductivity of the composites increases with increasing volume fraction of fiber because of the decrease in density. The specific thermal conductivity in the transverse directions is influenced more by the decrease in the absolute thermal conductivity than the decrease in density. As a result, the specific thermal conductivity decreases with increasing volume fraction of graphite fiber. However, it is important to note that the transverse thermal conductivities of composites with 20 to $50 \mathrm{vol} \%$ graphite fibers retain more than 50 percent of the specific thermal conductivity of pure copper.

Figure 17 also shows the specific thermal conductivity for $\mathrm{Be}$, a Ti-based alloy, a $\mathrm{Nb}$-based alloy, and a superalloy. Ti-based and $\mathrm{Nb}$-based alloys are suggested candidate alloys for applications above $700 \mathrm{~K}$. While the transverse specific thermal conductivity of the $\mathrm{Gr} / \mathrm{Cu}$ composites is less than copper and beryllium, it is significantly better than competitive titanium- and niobium-based alloys and superalloys. Even if beryllium were to be considered for use at this temperature, $\mathrm{Gr} / \mathrm{Cu}$ composites with more than 35 vol $\%$ graphite fibers have higher specific longitudinal thermal conductivities than beryllium, making them a better choice.

In most applications the composites need to be angle- or cross-plied to provide the desired properties. The thermal conductivity of a cross-plied 50 vol \% graphite composite having an equal number of $0^{\circ}$ and $90^{\circ}$ plies is shown in Fig. 18. The thermal conductivity of a unidirectional $50 \mathrm{vol} \%$ graphite composite is also shown for comparison. The rule of mixtures would predict that the longitudinal and long transverse directions would have a thermal conductivity equal to the average of the values for the unidirectional composite which is the observed behavior.

The short transverse thermal conductivity of the cross-plied composite is also shown in Fig. 18. The samples apparently have a higher thermal diffusivity in the short trans- verse direction compared to the unidirectional composite. The result is a curve that parallels the unidirectional short transverse curve with thermal conductivity values $25 \mathrm{~W} / \mathrm{mK}$ higher than the unidirectional values.

\section{Thermal Expansion of $\mathrm{Gr} / \mathrm{Cu}$ Composites}

The thermal expansions of the unidirectionally reinforced $\mathrm{Gr} / \mathrm{Cu}$ composites produced by the arc spray process are shown in Fig. 19. Pure copper is also included for comparison purposes. The long transverse thermal expansions fall in a narrow band that is independent of graphite fiber volume fraction. The values of the thermal expansion of the composites is greater than pure copper. No direct experimental data is available for the CTE of P100 fibers in the radial direction, but data is available for oriented pyrolytic (OP) graphite. $^{20}$ OP graphite has a CTE greater than copper in the direction of the $\mathrm{c}$ axis. This is the direction equivalent to the radial direction of the fiber. The larger CTE of the fibers in the radial direction would lead to increased thermal expansions in the long transverse directions as seen in the results.

The thermal expansions of the $\mathrm{Gr} / \mathrm{Cu}$ composites in the longitudinal direction shown in Fig. 19 are between the values for copper and P100 Gr fibers. The curves also show a rather unique behavior. As typified by the copper curve, the thermal expansion of most materials increases with increasing temperature. For the 20 vol $\% \mathrm{Gr} / \mathrm{Cu}$ composite, the thermal expansion curve is nearly parallel to the copper curve but at a lower value. The lower thermal expansion of the $\mathrm{Gr} / \mathrm{Cu}$ composites was expected since the contraction of the fibers during heating would restrain the copper matrix. What was not expected was the shape of the other curves.

The 30 and 40 vol \% graphite composites initially behave like the copper and 20 vol \% graphite curves. The thermal expansion increases with increasing temperature. At higher temperatures the 30 and 40 vol \% graphite curves deviate negatively from linear. 
The samples have a nearly constant thermal expansion above 750 and $500 \mathrm{~K}$, respectively. Analysis of the $\mathrm{Gr} / \mathrm{Cu}$ composite system has shown that thermally induced stresses from the CTE mismatch between the fibers and matrix can induce compressive yielding of the copper matrix at temperatures as low as 400 to $450 \mathrm{~K}$. Compressive yielding of the matrix would result in thermal expansions that are less than would occur without yielding. The calculated temperatures are lower than the temperatures at which the $30 \mathrm{vol} \%$ graphite composite show a deviation, but the calculated temperature for the $\mathbf{4 0} \mathrm{vol} \%$ graphite composite is in reasonable agreement with the data. The actual temperature at which yielding occurs would be dependent on slippage at the interface due to a poor bond and residual stresses produced in the composites during cooling from the HIPing temperature. Both could increase the actual yielding temperature. For the 50 vol $\%$ graphite composite, the thermal expansion of the composite is totally dominated by the fiber. As a result, the thermal expansion is near zero to slightly negative over the entire temperature range tested.

The thermal expansion behavior of the composites during cooling was also examined. Figure 20 shows the thermal expansion of a $20 \mathrm{vol} \% \mathrm{Gr} / \mathrm{Cu}$ composite in the longitudinal direction. As noted earlier, the 20 vol \% $\mathrm{Gr} / \mathrm{Cu}$ composite has a thermal expansion during heating that is similar to $\mathrm{Cu}$. On cooling the composite initially follows the heating curve, but it is offset by about 0.1 percent. At approximately $650 \mathrm{~K}$ the cooling curve levels off to a near constant thermal expansion over the temperature range of 298 to $650 \mathrm{~K}$. This behavior has also been observed in the other unidirectional and cross-plied samples tested to varying degrees. In all cases that the thermal expansion curves show a hysteresis, a measurable change in the length of the sample following thermal exposure was measured.

The hysteresis of the thermal expansion curves can be explained by the CTE mismatch between the fibers and matrix and yielding of the matrix during the thermal cycle. As explained earlier, the matrix undergoes a compressive stress during heating which causes yielding and decreases the thermal expansion. During cooling the graphite fibers expand and the copper matrix shrinks. As a result, the stress state of the composite is reversed so that the fibers are in compression and the matrix is in tension. Some temperature change is needed to accomplish this change in stress states. During this time the composite shows a decrease in length with temperature like a monolithic material. At some point, however, the stresses in the matrix exceed the tensile yield strength of the copper and tensile yielding occurs. The magnitude of the positive elongation due to yielding is nearly equal to the negative elongation due to cooling. The composite therefore shows a virtually constant length during cooling once the tensile yielding begins.

As the volume fractions of $\mathrm{Gr}$ fibers increases, the temperature at which tensile yielding begins increases. This is caused by the ability of the fibers to generate greater stresses in the matrix at the higher volume fractions. In the most extreme case tested, samples with 50 vol \% Gr fibers show essentially no contraction in length during cooling from $1073 \mathrm{~K}$.

The hysteresis loop and other phenomena observed during the study of the $\mathrm{Gr} / \mathrm{Cu}$ composites has led to interest in developing an engineered interface in the $\mathrm{Gr} / \mathrm{Cu}$ composites. By improving the bond between the fibers and matrix the strength of the composites can be improved, and the hysteresis in the thermal expansion curves can be minimized or eliminated. The engineered interface would be introduced by either coating the fiber with an element or compound, i.e., Mo or $\mathrm{NbC}$, or utilizing an alloy matrix that will react with the fibers to form a bond, i.e., a $\mathrm{Cu}-\mathrm{Cr}$ alloy. The cost of coating fibers with an element or compound prior to copper coating is, however, very high. The copper coating process is also limited to a pure copper matrix, making it impossible to produce an alloyed matrix. 
These problems make the arc spray process unsuitable for producing composites with engineered interfaces. Interest is currently being focussed on pressure infiltration casting of $\mathrm{Gr} / \mathrm{Cu}$ composites. Some samples using alloy matrices and coated $\mathrm{Gr}$ fibers have already been successfully produced. Testing is in progress to determine if the pressure infiltration cast composites with an engineered interface are better that the arc spray produced composite. Preliminary results look extremely promising.

\section{Summary of Results}

(1) The PWC-11 alloy is four times more creep resistant then the $\mathrm{Nb}-1 \% \mathrm{Zr}$ alloy at $1350 \mathrm{~K}$.

(2) The PWC-11 alloy has demonstrated its superior creep strength over the $\mathrm{Nb}-1 \% \mathrm{Zr}$ alloy for times in excess of $35000 \mathrm{~h}$.

(3) The thermal stability and creep strength of PWC-11 is enhanced by the precipitation of the $70 / 30(\mathrm{Zr} / \mathrm{Nb})$ monocarbide $(\mathrm{Zr}, \mathrm{Nb}) \mathrm{C}$.

(4) The creep properties of $\mathrm{W} / \mathrm{Nb}$ composites at $1500 \mathrm{~K}$ exceed rule of mixtures calculated values. The creep resistance of these composites significantly exceeds that of monolithic niobium alloys even when compared on a density basis.

(5) The creep-rupture strength of the $\pm 15^{\circ}$ angle-plied fiber $\mathrm{W} / \mathrm{Nb}$ composite exceeds that of the PWC-11 by a factor of four.

(6) Interdiffusion between tungsten and niobium did not significantly degrade the creep strength of the composite at times up to $5000 \mathrm{hr}$.

(7) The specific thermal conductivity of $\mathrm{Gr} / \mathrm{Cu}$ composites in the longitudinal direction is far superior to that of copper, titanium alloys, and niobium alloys. The specific thermal conductivity of $\mathrm{Gr} / \mathrm{Cu}$ composites is comparable to that of beryllium at low temperatures and is better at higher temperatures.

(8) The long transverse thermal expansion of unidirectional $\mathrm{Gr} / \mathrm{Cu}$ composites is greater than the thermal expansion of copper. The longitudinal thermal expansion is less than copper and strongly dependent on the volume fraction of graphite fibers. Cross-plied composites have thermal expansions between the longitudinal and the long transverse values, but they do not follow the rule of mixtures.

\section{$\underline{\text { Conclusions }}$}

The results to date show that for space power and propulsion systems operating in the 1350 to $1450 \mathrm{~K}$ temperature range: (1) the PWC-11 alloy exceeds the creep strength and thermal stability requirements for the SP-100 design and will replace $\mathrm{Nb}-1 \% \mathrm{Zr}$ in the Flight Qualification System, (2) the creep strength of the $\mathrm{W} / \mathrm{Nb}$ composites exceed that of the monolithic niobium alloys and offer more growth potential than niobium alloys, and (3) the thermal conductivity and thermal expansion of $\mathrm{Gr} / \mathrm{Cu}$ composites can be engineered to the heat rejection system geometry. These materials have been developed and characterized to the extent that space power system designers now have additional options upon which to base their designs.

\section{$\underline{\text { References }}$}

1. Titran R.H., "Creep Strength of Niobium Alloys, $\mathrm{Nb}-1 \% \mathrm{Zr}$ and PWC-11," DOE/NASA/16310-13, NASA-TM-1023-90, 1990.

2. DelGrosso, E.J., Carlson, E.C., and Kaminsky, J.J., "Development of Niobium-Zirconium-Carbon Alloys," Journal of the Less Common Metals, Vol. 12, 1967, pp. 173-201. 
3. Titran, R.H., Moore, T.J., and Grobstein, T.L., "Creep Behavior of Niobium Alloy PWC-11,"DOE/NASA/16310-3, NASA TM-89834, 1986.

4. Grobstein, T.L., and Titran, R.H., "Characterization of Strengthening Precipitates in a Nb-Zr-C Alloy," DOE/NASA/16310-6, NASA TM-100848, 1986.

5. Uz, M., and Titran, R.H., "Thermal Stability of the Microstructure of an Aged Nb-Zr-C Alloy," DOE/NASA/16310-14, NASA TM-103647, 1990.

6. Orr, R.L., Sherby, O.D., and Dorn, J.E., "Correlations of Rupture Data for Metals at Elevated Temperatures," Transactions ASM, Vol. 46, 1954, pp. 113-128.

7. Westfall, L.J., "Tungsten Fiber Reinforced Superalloy Composite Monolayer Fabrication by an Arc-Spray Process," NASA TM-86917, 1986.

8. Petrasek, D.W., and Titran, R.H., "Creep Behavior of Tungsten/Niobium-1 Percent Zirconium Composites," DOE/ NASA/16310-5, NASA TM-100804, 1988.

9. Hoffman, E.E., and Harrison, R.W., "The Compatibility of Refractory Metals with Liquid Metals," Report GESP-15, 1968.

10. Armstrong, H.H., Ellison, A.M., and Kilntis, D.H., "Development of Graphite/Metal Composites for Spacecraft Applications," AF W AL-TR-834148, Air Force Systems Command, 1983. (Avail. NTIS, AD-B084756.)

11. Brandes, E.A., Smithells Metals Reference Book, Sixth Ed., Butterworths, London, 1983, p. 14-1.
12. Designing with Beryllium, Brush Wellman, Inc., Cleveland, OH.

13. McDanels, D.L., and Diaz, J.O., "Exploratory Feasibility Studies of Graphite Fiber Reinforced Copper Matrix Composites for Space Power Radiator Panels," NASA TM-102328, 1989.

14. Thornel Product Information, AMOCO Performance Products, Inc., Atlanta, GA.

15. Brandes, E.A., Smithells Metals Reference Book, Sixth Ed., Butterworths, London, 1983, p. 14-3.

16. Naidich, Y.V., and Kolesnichenko, G.A., "Laws Governing the Contact Interaction of Graphite With Molten Metals," Izvestia Akademia Nauk SSR, Metally, Vol. 4, July-Aug. 1968, pp. 222-230.

17. Buckman, M.A., Bentsen, L.D., Makosey, J., Angell, G.R., and Hasselman, G.P.H., "The Measurement of the Thermal Conductivity of Refractories by the Laser-Flash Method," Transactions, British Ceramic Society, Vol. 82, No. 1, 1983, pp. 18-23.

18. Schultz, D.A., Proceedings 6th Metal Matrix Composites Technology Conference, MMCIAC-000673, MMCIAC, Santa Barbara, CA, 1985, pp. 29/1-14.

19. Touloukin, Y.S., Kirby, R.K., Taylor, R.E., and Lee, T.Y.R., Thermophysical Properties of Matter, Vol. 13, Thermal Expansion, Nonmetallic Solids, IFI/ Plenum, New York, NY, 1977, p. 79. 
TABLE 1. - CHARACTERIZATION OF PRECIPITATES IN PWC-11

\begin{tabular}{|c|c|c|c|}
\hline & As-rolled & $\begin{array}{c}\text { After initial } \\
\text { heat treatment }\end{array}$ & $\begin{array}{l}\text { After long-term } \\
\text { high-temperature } \\
\text { exposure }\end{array}$ \\
\hline $\begin{array}{l}\text { Size, } \mu \mathrm{m} \\
\text { Structure } \\
\text { Composition }\end{array}$ & $\begin{array}{l}1 \text { to } 10 \\
\mathrm{HCP} \\
\mathrm{Nb}_{2} \mathrm{C}\end{array}$ & $\begin{array}{c}0.05 \text { to } 0.01 \\
\text { FCC } \\
(\mathrm{Zr}, \mathrm{Nb}) \mathrm{C}\end{array}$ & $\begin{array}{l}0.1 \text { to } 0.15 \\
\text { FCC } \\
(\mathrm{Zr}, \mathrm{Nb}) \mathrm{C}\end{array}$ \\
\hline
\end{tabular}

${ }^{\text {a }}$ Conclusions: Aging at 1350 or $1400 \mathrm{~K}$ with an applied stress does not "overage" the precipitates. After long times $(35000 \mathrm{~h})$ at $1350 \mathrm{~K}$, the precipitates are still effective at pinning dislocations and resisting plastic deformation in creep.

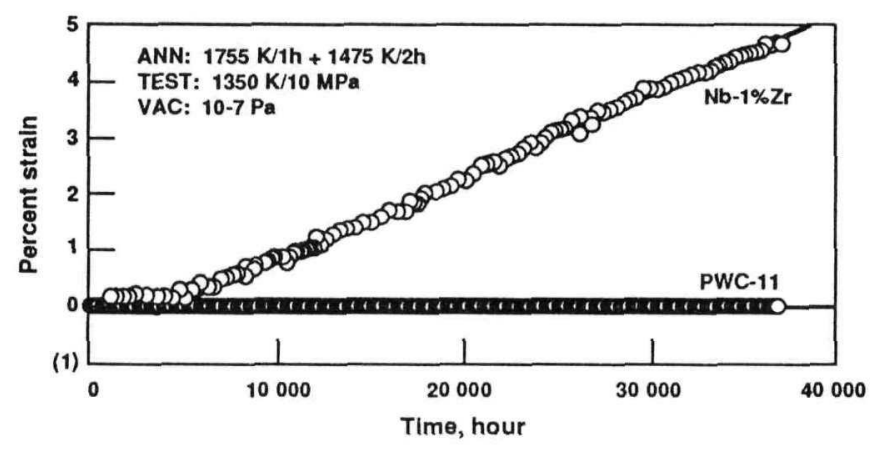

Figure 1.-Creep curves for $\mathrm{Nb}-1 \% \mathrm{Zr}$ and the $0.062 \% \mathrm{C}$ PWC-11 alloy tested at indicated conditions.

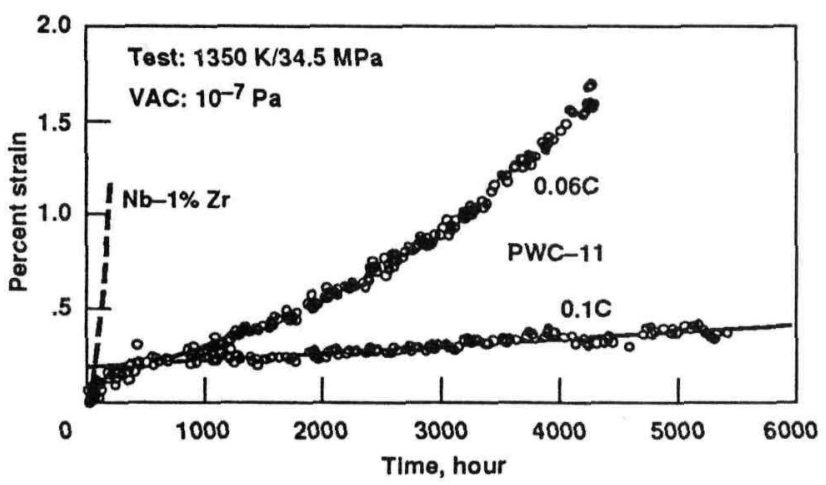

Figure 2.-Creep curves for $\mathrm{Nb}-1 \% \mathrm{Zr}$ and the 0.062 and $0.01 \% \mathrm{C}$ PWC-11 alloy at indicated test conditions.

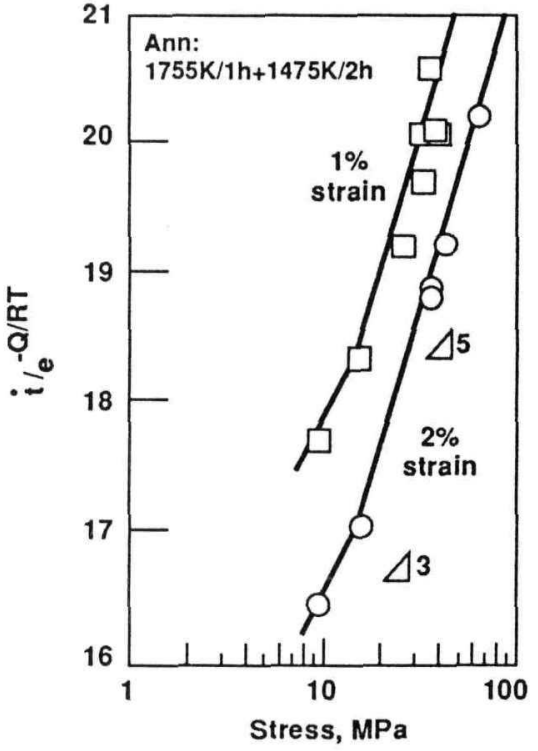

Figure 3.-Temperature compensated time to $1 \%$ and $2 \%$ creep strain versus stress for $\mathrm{Nb}-0.9 \% \mathrm{Zr}-0.06 \%$ C PWC-11 alloy. 


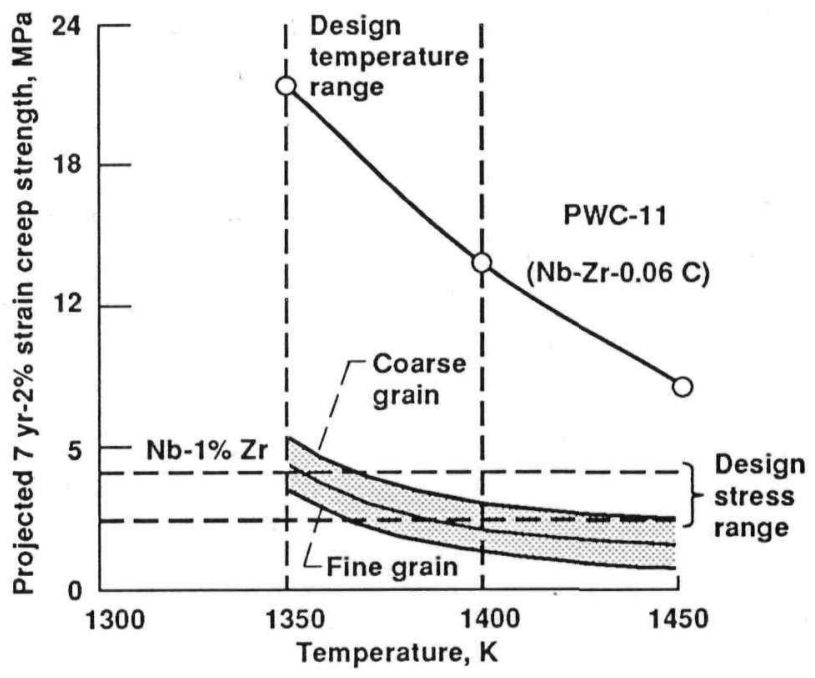

Figure 4.-Projected 7 year temperature and creep strength potential for PWC-11 and $\mathrm{Nb}-1 \% \mathrm{Zr}$.

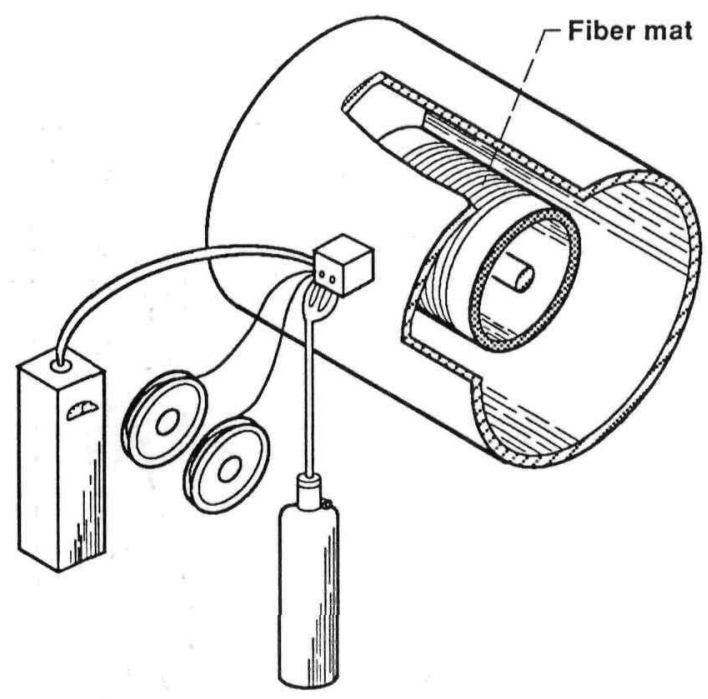

Overall view

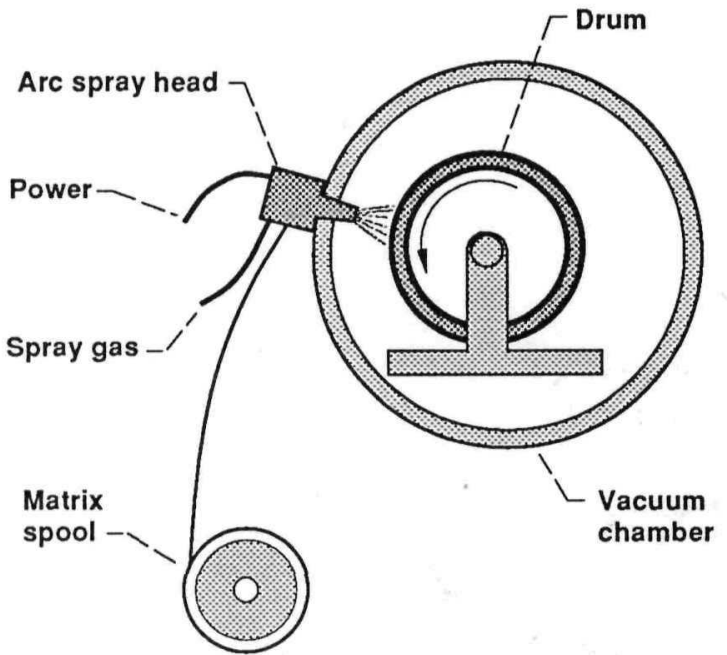

Schematic of operation

Figure 5.-Schematized NASA-Lewis Research Center patented arc-spray monotape technique. 
Nb Matrix Fiber

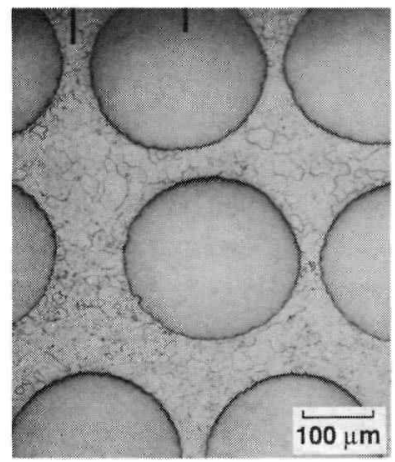

Nb Matrix Fiber

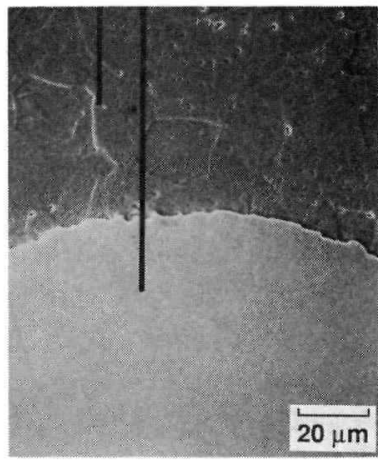

Figure 6.-Photomicrographs of the as-fabricated microstructure of a $\mathrm{W} / \mathrm{Nb}$ composite illustrating the minimal interdiffusion between $\mathrm{W}$ and $\mathrm{Nb}$.

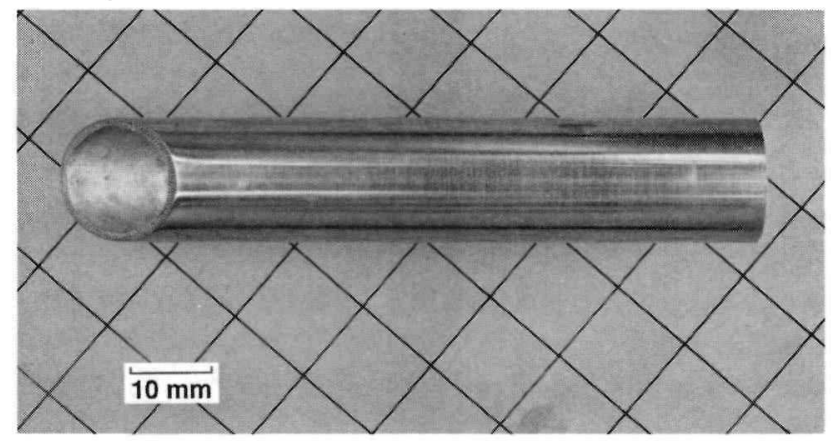

Figure 7.-W/Nb composite tube, $15 \mathrm{~mm}$ inner diameter with $3 \mathrm{~mm}$ wall, fabricated from arc-spray monotapes. 
- ST300-W High strength tungsten wire $\mathrm{W} / 1.5 \% \mathrm{ThO}_{2}$

-218CS-W Commercial tungsten lamp filament wire

35 v/o ST300-W/Nb-1\% Zr composite

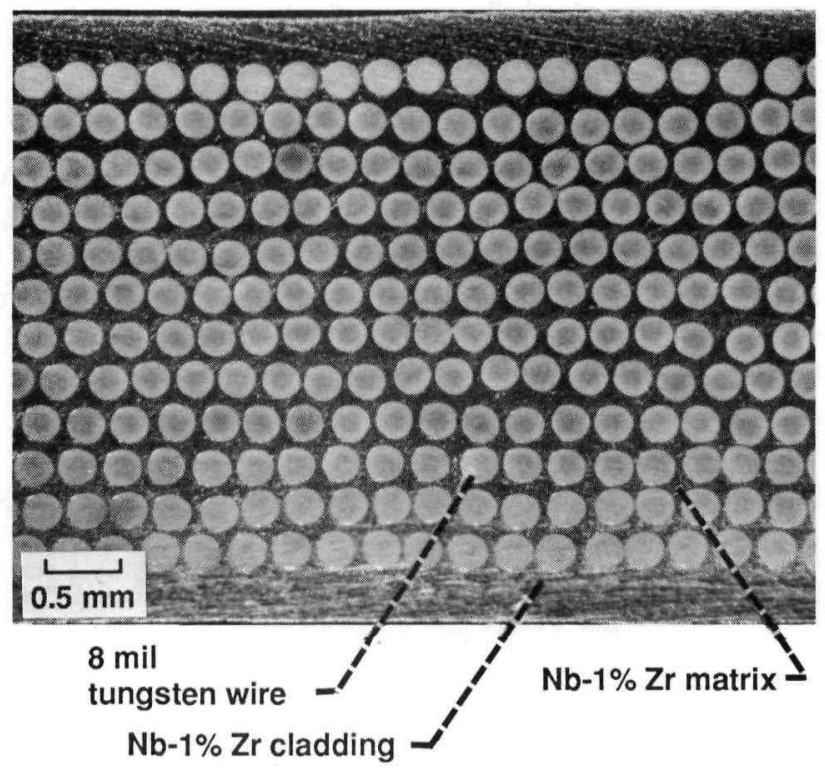

Comparison of tensile strength/density ratios of $42 \mathrm{v} / \mathrm{o}$ W/unalloyed $\mathrm{Nb}$ composites with conventional $\mathrm{Nb}$ alloys

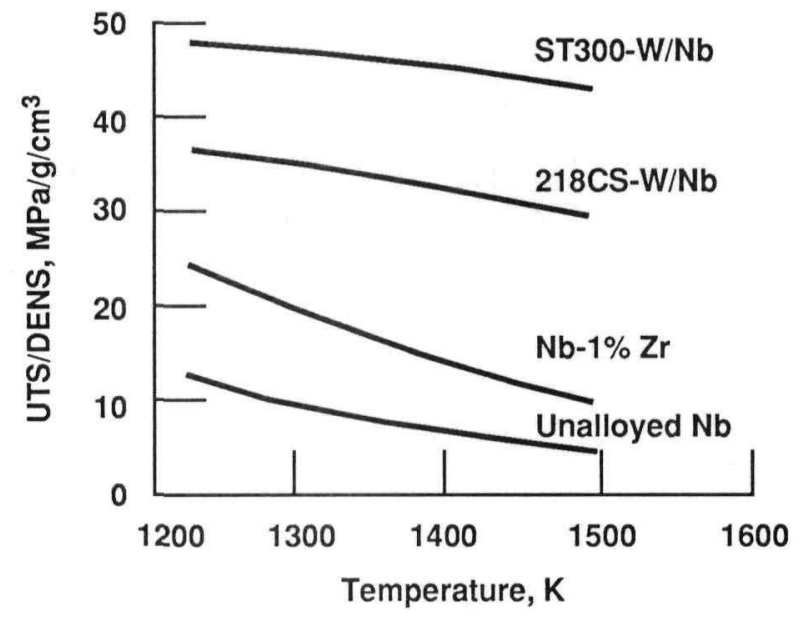

Figure 8.-Macrograph of the microstructure of a ST300/ $\mathrm{Nb}-1 \% \mathrm{Zr}$ composite and comparison of tensile strength of composite to monolithic matrix materials. 


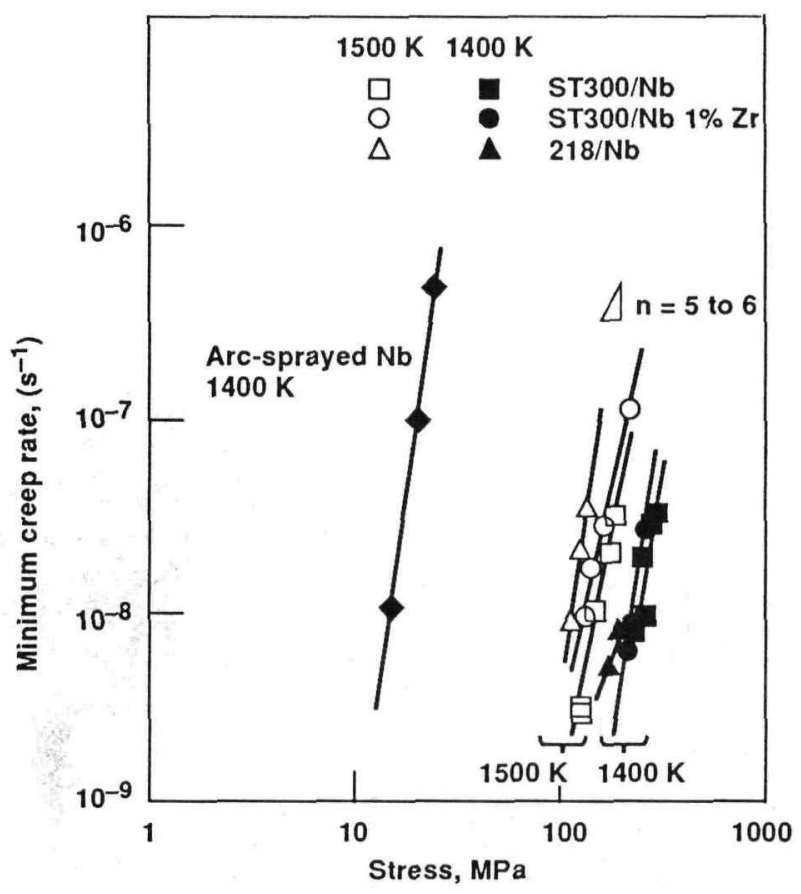

Figure 9.-Comparison of minimum creep rate for composites and arc-sprayed $\mathrm{Nb}$. Composites normalized to 50 vol\% fiber content.

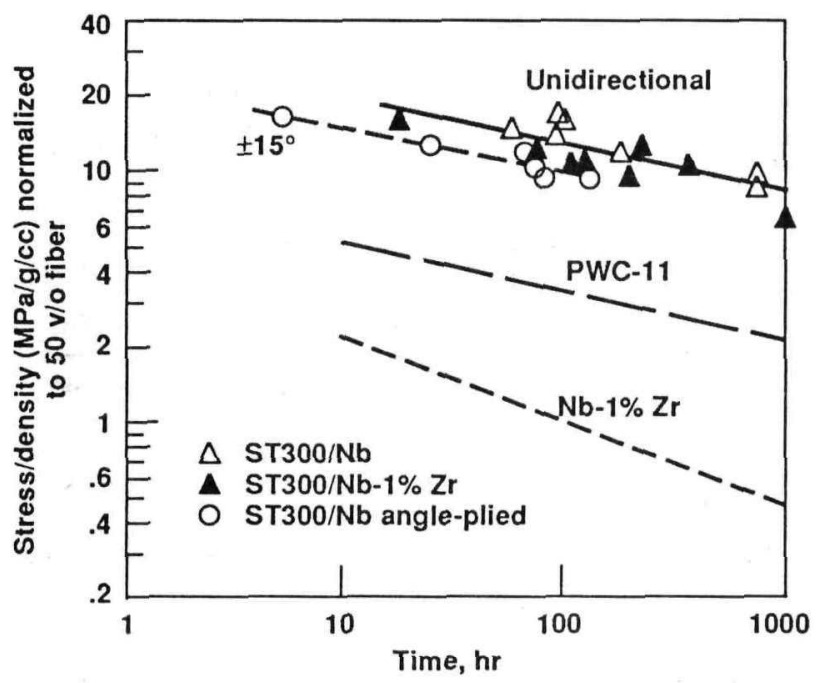

Figure 11.-Comparison of the $1500 \mathrm{~K}$ time to 1 percent creep strain versus the specific creep strength of the W/Nb composite materials and competitive monolithic niobium alloys.

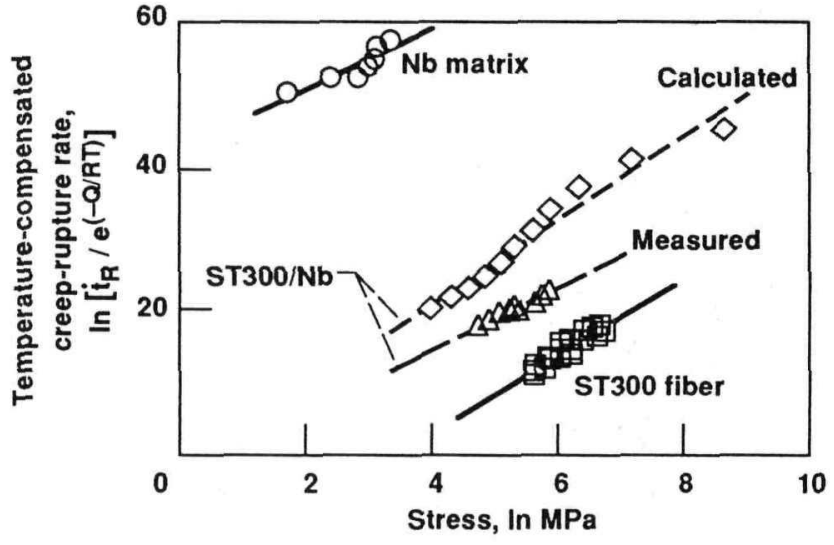

Figure 10.-The measured creep-rupture values of the ST300/Nb composite exceed the rule-of-mixtures calculated values.

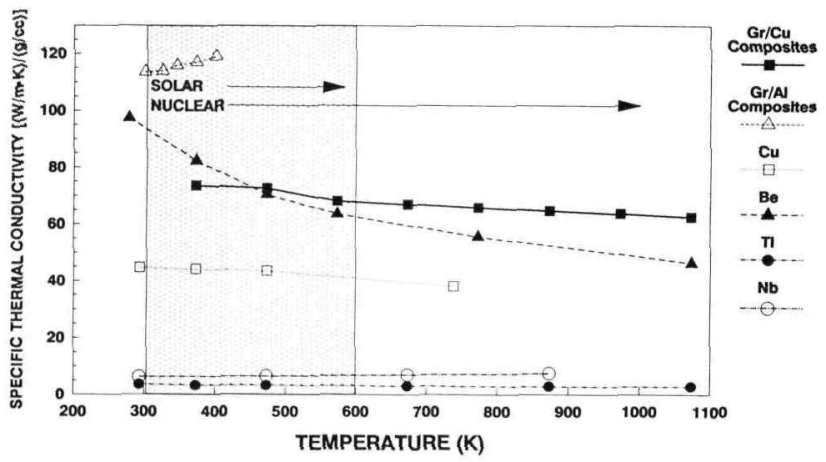

Figure 12.-Specific thermal conductivity versus temperature for six candidate space power radiator fin materials. 


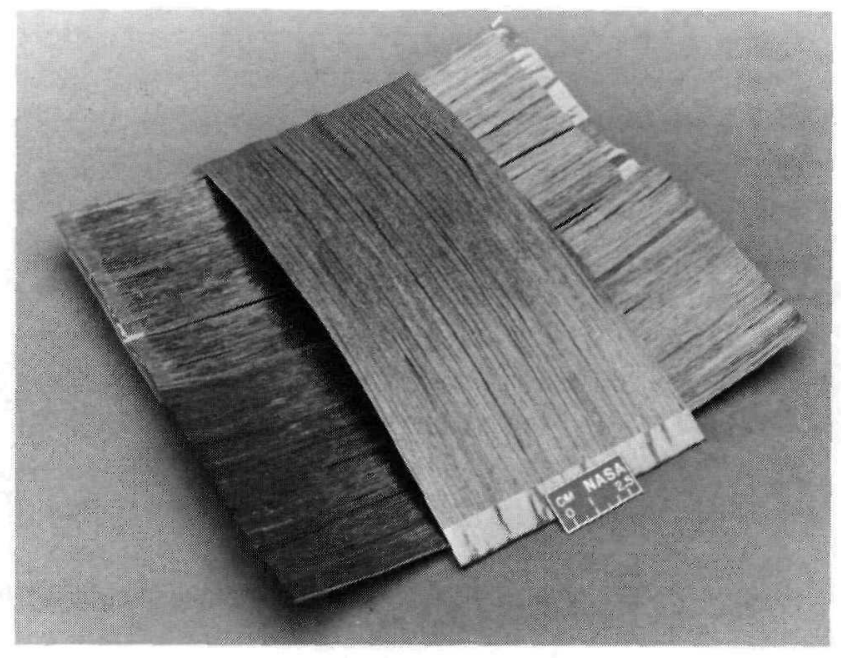

Figure 13.- $-\mathrm{Gr} / \mathrm{Cu}$ monotapes produced by the arc spray process.

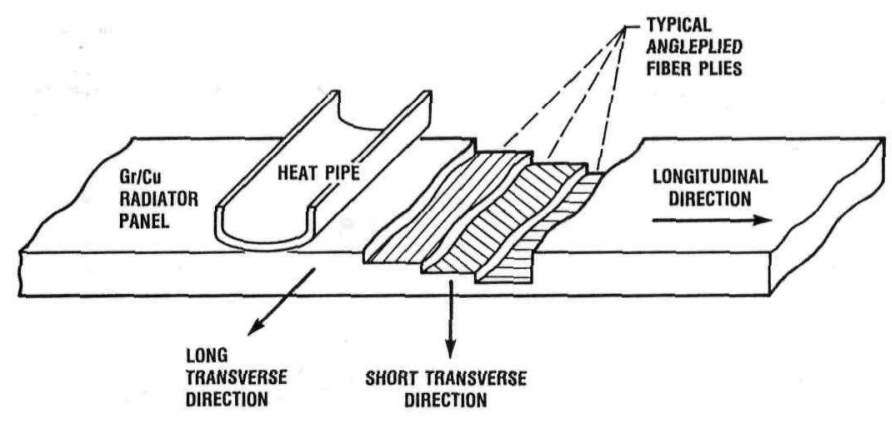

Figure 15.- $\mathrm{Gr} / \mathrm{Cu}$ radiator fin showing three principle directions.

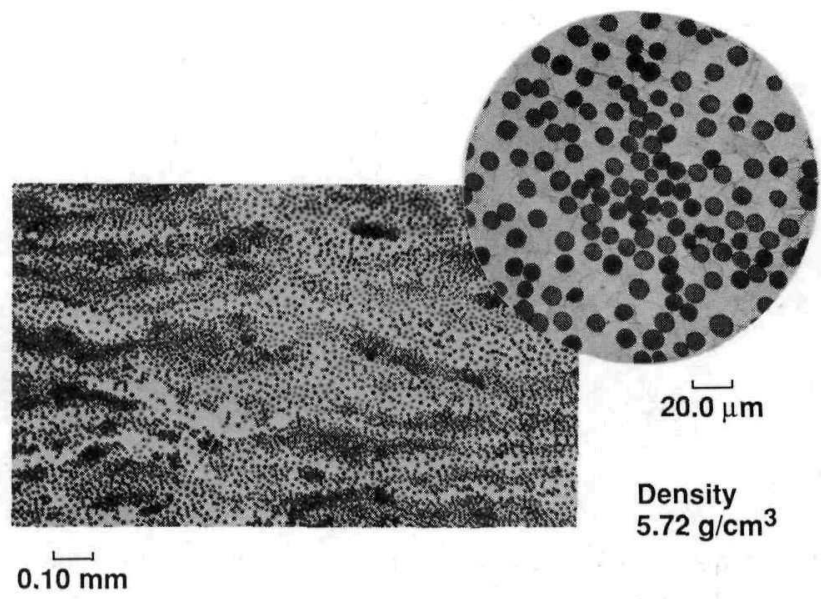

Figure 14.-Microstructure of $50 \mathrm{v} / \mathrm{o} \mathrm{Gr} / \mathrm{Cu}$ composite produced by arc spray process

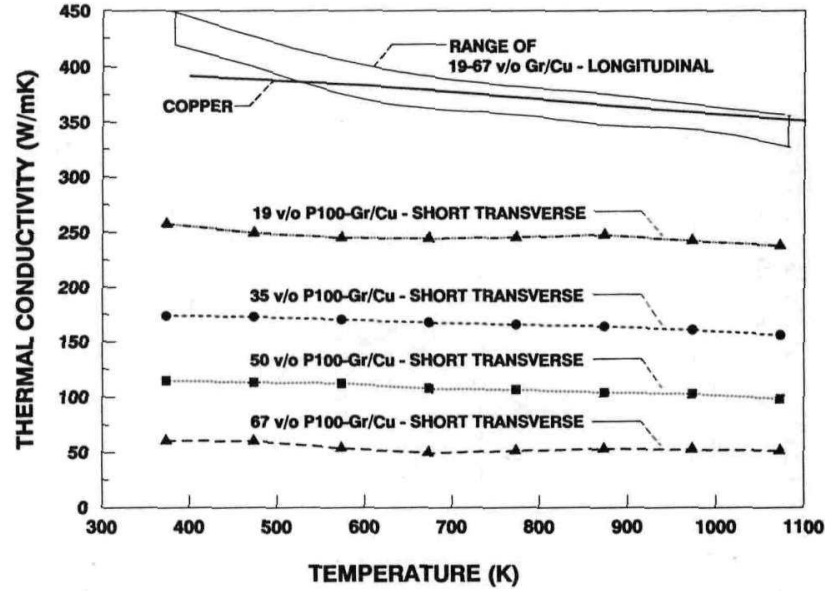

Figure 16.-Thermal conductivity of unidirectionally reinforced $\mathrm{Gr} / \mathrm{Cu}$ composites between $298 \mathrm{~K}$ and $1073 \mathrm{~K}$. 


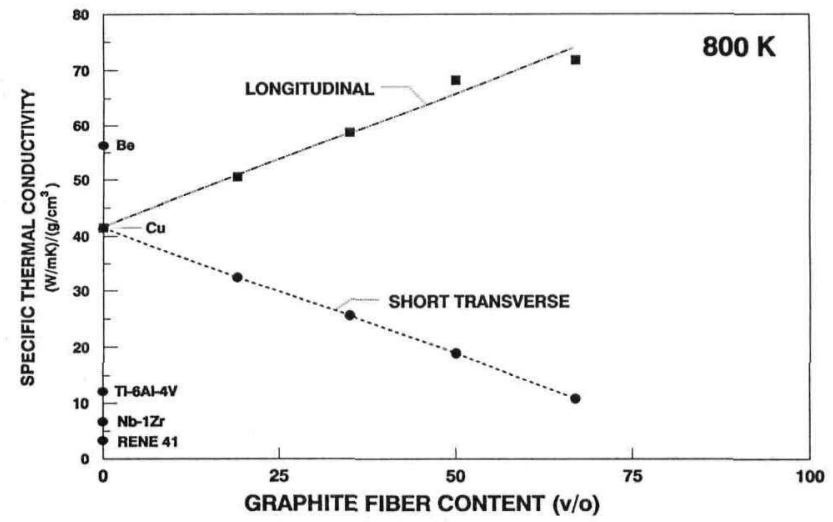

Figure 17.-Specific Gr/Cu composite thermal conductivity at $800 \mathrm{~K}$ versus fiber content for the longitudinal and short transverse directions.

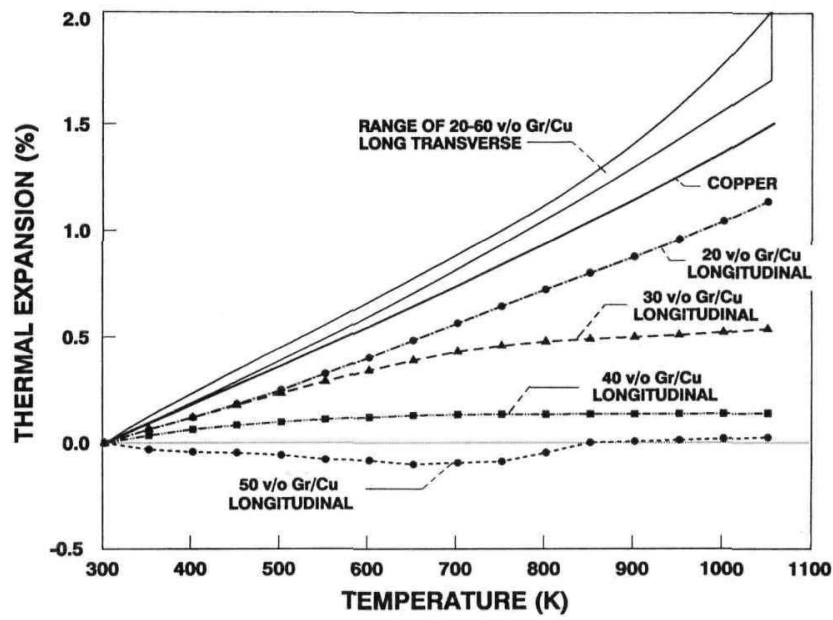

Figure 19.- Thermal expansion of unidirectionally reinforced $\mathrm{Gr} / \mathrm{Cu}$ composites between $298 \mathrm{~K}$ and $1073 \mathrm{~K}$. Heating curve only.

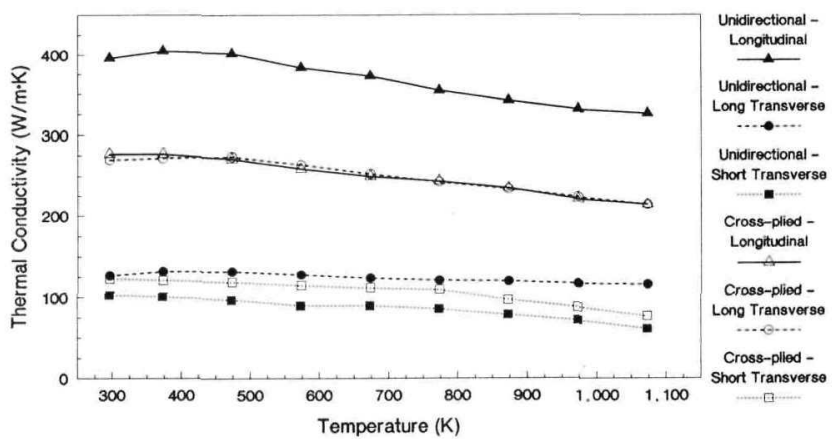

Figure 18.-Thermal conductivity of cross-plied and unidirectional $50 \mathrm{v} / 0 \mathrm{Gr} / \mathrm{Cu}$ composites between $298 \mathrm{~K}$ and $1073 \mathrm{~K}$.

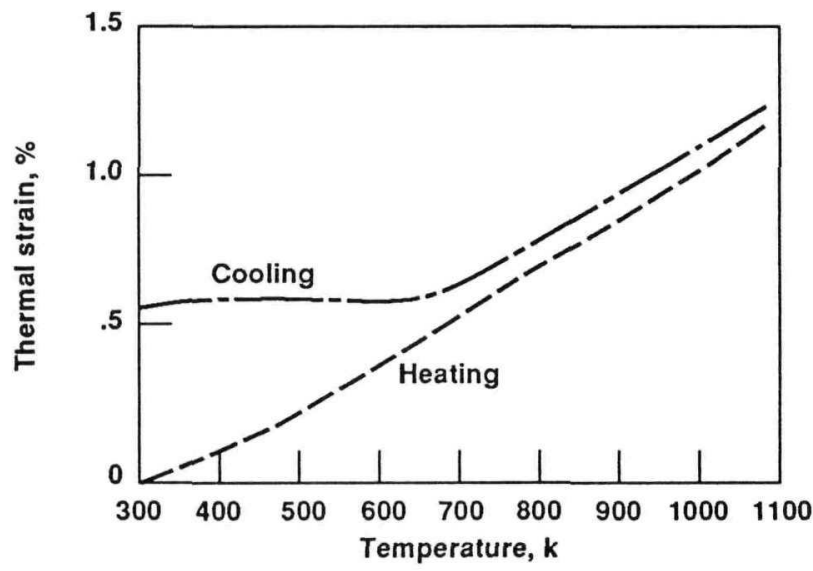

Figure 20.-Thermal expansion of $20 \mathrm{v} / 0 \mathrm{Gr} / \mathrm{Cu}$ composite in the longitudinal direction between $298 \mathrm{~K}$ and $1083 \mathrm{~K}$. Heating and cooling curves. 


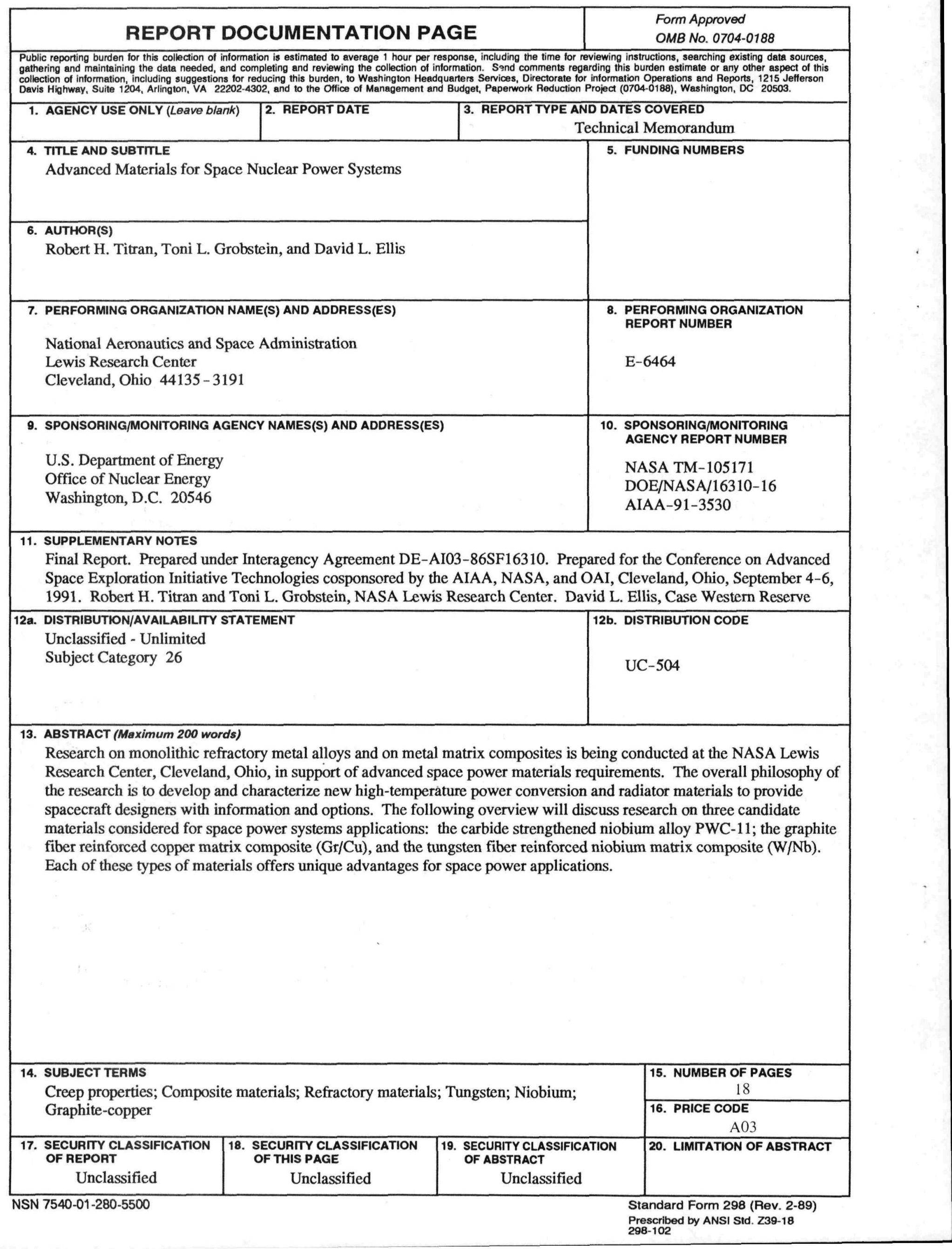

